\title{
Vonoprazan: MarKed Competition for PPIs?
}

\author{
David R. Scott ${ }^{1,4}$ - Elizabeth A. Marcus ${ }^{2,4}$ - George Sachs G,3,4 $^{1,4}$
}

Published online: 13 April 2016

(c) Springer Science+Business Media New York 2016

Contemporary therapies for the treatment of acid-related diseases such as gastroesophageal reflux disease (GERD) and peptic ulcer disease (PUD), as well as Helicobacter pylori infection, rely on acid suppression for symptom relief, healing, and eradication, respectively. Inhibition of the gastric $\mathrm{H}^{+}, \mathrm{K}^{+}$-ATPase, the final step in the acid secretion pathway, by proton pump inhibitors has been the treatment of choice since the approval of omeprazole for clinical use 30 years ago [1]. PPIs were a vast improvement over the $\mathrm{H}_{2}$ receptor antagonists $\left(\mathrm{H}_{2} \mathrm{RAs}\right)$ and antacids for symptom relief and for healing of GERD and PUD.

PPIs are weak bases that accumulate in the acidic $(\mathrm{pH} \sim 1)$ secretory canaliculus of the gastric parietal cells. Being prodrugs, they require protonation to achieve their active form. Once protonated, they rapidly and irreversibly bind to and inhibit actively secreting proton pumps in the canalicular membrane. Because not all proton pumps are active at any one time and PPIs are not present at effective concentrations after a single administration, several doses are required to inhibit newly active pumps and to achieve steady-state inhibition of acid secretion. To inhibit as many pumps as possible with a single PPI dose, the drug must be administered about $30 \mathrm{~min}$ before a meal to ensure the

David R. Scott

dscott@ucla.edu

1 Department of Physiology, DGSOM at UCLA, Los Angeles, CA, USA

2 Department of Pediatrics, DGSOM at UCLA, Los Angeles, CA, USA

3 Department of Medicine, DGSOM at UCLA, Los Angeles, CA, USA

4 VA GLAHS, 11301 Wilshire Blvd., Bldg. 113, Rm. 324, Los Angeles, CA, USA maximal number of pumps is present at the canalicular membrane, due to the effects of post-prandial gastrin release. Furthermore, since the $t_{1 / 2}$ of the $\mathrm{H}^{+}, \mathrm{K}^{+}$-ATPase is $\sim 50 \mathrm{~h}$, de novo synthesized pumps account for $\sim 25 \%$ of active pumps daily [2]. Nocturnally synthesized pumps are not inhibited by PPIs given either once or twice daily due to the short (60-90 min) plasma $t_{1 / 2}$ of the drug. Together, these processes contribute to a slow onset of acid inhibition, with $\sim 40 \%$ inhibition of the pumps with the first dose and $\sim 70$ or $80 \%$ at steady state after 3 days of treatment at either once a day or twice a day dosing, respectively [3].

PPIs are metabolized in the liver by cytochrome CYP2C19 [4], polymorphisms of which affect the pharmacokinetics and pharmacodynamics of the medication. The phenotypes of the CYP2C19 polymorphisms are extensive or rapid metabolizers (RM), intermediate metabolizers (IM), and poor metabolizers (PM) [5]. The plasma "dwell time" of a single dose of omeprazole is directly correlated with the rate of metabolism among the different alleles with $\mathrm{PM}>\mathrm{IM}>\mathrm{RM}$, which in turn affects the level of acid inhibition, again with PM $>$ IM $>$ RM. The rate of metabolism affects the rate of healing of mucosal breaks in GERD patients, with RMs having the lowest cure rate and PMs the highest ( $\mathrm{RM}<\mathrm{IM}<\mathrm{PM})$. The difference in the rate of metabolism also influences the efficacy of $H$. pylori eradication, since the rate of eradication correlates well with the degree of acid inhibition. Although PPIs are superior to the $\mathrm{H}_{2} \mathrm{RAs}$ in terms of acid inhibition, there is still a need for a more potent, faster-acting acid inhibitor for better symptom relief and for mucosal healing.

An alternative mechanism of inhibition of the gastric $\mathrm{H}^{+}, \mathrm{K}^{+}$-ATPase was discovered during studies of dihydropyridine-based $\mathrm{Ca}^{2+}$ channel blockers (CCBs), which 
inhibited acid secretion in an experimental preparation of rabbit gastric glands due to $\mathrm{K}^{+}$-competitive inhibition of the $\mathrm{H}^{+}, \mathrm{K}^{+}$-ATPase. A novel compound based on the CCB structure, $\mathrm{SCH} 28080$, synthesized to mimic omeprazole, is a purely $\mathrm{K}^{+}$-competitive inhibitor of the $\mathrm{H}^{+}, \mathrm{K}^{+}$-ATPase [6] that is the first member of group of novel antisecretory drugs termed potassium competitive acid blockers (PCABs). This compound had a short duration of action and was hepatotoxic, as were other imidazopyridines such as soraprazan and AZD865, which suffered from similar disadvantages [7].

In this issue of Digestive Diseases and Sciences, Matsukawa et al. report that the PCAB vonoprazan selectively concentrates in gastric parietal cells in vivo [8], confirming their previous in vitro studies [9]. This finding, along with the slow clearance of vonoprazan from parietal cells reported in their earlier study, explains its potent and longlasting acid inhibitory properties due to reversible inhibition of gastric acid secretion by competing with $\mathrm{K}^{+}$on the luminal surface of the proton pump. Vonoprazan is a weak base $\left(\mathrm{p} K_{\mathrm{a}}\right.$ 9.06) that accumulates in the parietal cell canaliculi at concentrations of up to $10^{8}$-fold higher than in the blood ( $\mathrm{pH}$ 7.4) [10]. This inhibitor is highly selective for binding to the $\mathrm{H}^{+}, \mathrm{K}^{+}$-ATPase with a $K_{i}$ of $10 \mathrm{nM}$ and an $\mathrm{IC}_{50}$ of $17-19 \mathrm{nM}$ [10]. Binding, rapid and very slowly reversible, reaches a plateau of inhibition within $200 \mathrm{~s}$. The $t_{1 / 2}$ of dissociation is 4.7 and $7.5 \mathrm{~h}$ for rabbit and hog proton pumps, respectively [10]. Taken together, these parameters indicate that vonoprazan has the potential for rapid, reversible, and long-lasting inhibition of the gastric $\mathrm{H}^{+}, \mathrm{K}^{+}$-ATPase when compared to the PPIs. The unique properties of vonoprazan combined with its greater degree of acid inhibition as compared with the PPIs should provide greater efficacy in the treatment of acid-related diseases. Indeed, in a phase 1, randomized, double-blind, placebo-controlled, single rising-dose study, plasma vonoprazan concentrations peaked at $2 \mathrm{~h}$ at all doses tested $(1,5,10,15,20,30,40,80$, and $120 \mathrm{mg})$ [11]. In this study, the mean plasma $t_{1 / 2}$ of elimination was $5.1-8.7 \mathrm{~h}$ and was dose-dependent. There was dose dependency in the percent of time that intragastric $\mathrm{pH}$ was greater than $\mathrm{pH}$ $4(95 \%$ at $120 \mathrm{mg})$ and $\mathrm{pH} 5(93 \%$ at $129 \mathrm{mg})$ over a 24-h period. The efficacy of vonoprazan in patients with erosive esophagitis (EE) was investigated in a multicenter, randomized, double-blind, parallel-group, dose-ranging study [12]. Vonoprazan at 5, 10, 20, and $40 \mathrm{mg}$ was compared to the PPI lansoprazole at $30 \mathrm{mg}$ for healing of $\mathrm{EE}$ at 4 and 8 weeks. The percent of EE healing at 4 weeks for vonoprazan was between 92.3 and $97.0 \%$ and was dose-dependent, compared with $93.2 \%$ for lansoprazole.
The work of Matsukawa et al. provides physiologic mechanism for the clinical findings recently described in the literature and outlined above. Vonoprazan is able to exert a direct and targeted effect on the parietal cell, potently inhibiting acid secretion independently of the secretory state of the $\mathrm{H}^{+}, \mathrm{K}^{+}$-ATPase. This, combined with a metabolic pathway that is unaffected by CYP2C19 phenotype, provides promise for the use of PCABs for improved management of acid-related diseases, in particular for patients in whom PPIs are ineffective.

\section{References}

1. Lindberg P, Brandstrom A, Wallmark B, Mattsson H, Rikner L, Hoffmann KJ. Omeprazole: the first proton pump inhibitor. Med Res Rev. 1990;10:1-54.

2. Gedda K, Scott D, Besancon M, Lorentzon P, Sachs G. Turnover of the gastric $\mathrm{H}^{+}, \mathrm{K}^{+}$-adenosine triphosphatase alpha subunit and its effect on inhibition of rat gastric acid secretion. Gastroenterology. 1995;109:1134-1141.

3. Cederberg C, Lind T, Rohss K, Olbe L. Comparison of once-daily intravenous and oral omeprazole on pentagastrin-stimulated acid secretion in duodenal ulcer patients. Digestion. 1992;53:171-178.

4. Sakai T, Aoyama N, Kita T, et al. CYP2C19 genotype and pharmacokinetics of three proton pump inhibitors in healthy subjects. Pharm Res. 2001;18:721-727.

5. Furuta T, Shirai N, Ohashi K, Ishizaki T. Therapeutic impact of CYP2C19 pharmacogenetics on proton pump inhibitor-based eradication therapy for Helicobacter pylori. Methods Find Exp Clin Pharmacol. 2003;25:131-143.

6. Wallmark B, Briving $\mathrm{C}$, Fryklund $\mathrm{J}$, et al. Inhibition of gastric $\mathrm{H}^{+}, \mathrm{K}^{+}$-ATPase and acid secretion by $\mathrm{SCH} 28080$, a substituted pyridyl(1,2a)imidazole. J Biol Chem. 1987;262:2077-2084.

7. Andersson K, Carlsson E. Potassium-competitive acid blockade: a new therapeutic strategy in acid-related diseases. Pharmacol Ther.. 2005;108:294-307.

8. Matsukawa J, Kogame A, Tagawa Y, Inatomi N. Radiographic localization study of a novel potassium-competitive acid blocker, vonoprazan, in the rat gastric mucosa. Dig Dis Sci. (Epub ahead of print). doi:10.1007/s10620-016-4100-y.

9. Matsukawa J, Hori Y, Nishida H, Kajino M, Inatomi N. A comparative study on the modes of action of TAK-438, a novel potassium-competitive acid blocker, and lansoprazole in primary cultured rabbit gastric glands. Biochem Pharmacol. 2011;81:1145-1151.

10. Shin JM, Inatomi N, Munson K, et al. Characterization of a novel potassium-competitive acid blocker of the gastric H,K-ATPase, 1-[5-(2-fluorophenyl)-1-(pyridin-3-ylsulfonyl)-1H-pyrrol-3-yl]$\mathrm{N}$-methylmethanamin e monofumarate (TAK-438). J Pharmacol Exp Ther. 2011;339:412-420.

11. Sakurai Y, Nishimura A, Kennedy G, et al. Safety, tolerability, pharmacokinetics, and pharmacodynamics of single rising TAK438 (vonoprazan) doses in healthy male Japanese/non-Japanese subjects. Clin Transl Gastroenterol. 2015;6:e94.

12. Ashida K, Sakurai Y, Nishimura A, et al. Randomised clinical trial: a dose-ranging study of vonoprazan, a novel potassiumcompetitive acid blocker, vs. lansoprazole for the treatment of erosive oesophagitis. Aliment Pharmacol Ther. 2015;42:685-695. 